\title{
Education, Science and Culture gets more in Japan
}

\section{- Space and nuclear physics to benefit - Compensation for postdoc exodus}

\section{Tokyo}

JAPAN's Ministry of Education, Science and Culture has won some huge increases for its science-related budget in fiscal year 1988. The ministry's requests submitted in September (see Nature 329, 187; 1987) were trimmed back during final negotiations with the Ministry of Finance at the end of last year. Nevertheless, the budget is up nearly 20 per cent on last year.

The education ministry's science budget stands in stark contrast to those of the Science and Technology Agency and Ministry of International Trade and

\begin{tabular}{|c|c|c|c|c|}
\hline & 1986 & 1987 & 1988 & ( $\%$ change \\
\hline & (thousa & ind milli & on yen) & from 1987$)$ \\
\hline Grants-in-aid of research & 43.5 & 45.1 & 48.9 & $(+8.4)$ \\
\hline $\begin{array}{l}\text { Maintenance of scientific research } \\
\text { system }\end{array}$ & $\mathrm{NA}^{*}$ & NA & 1.7 & \\
\hline $\begin{array}{l}\text { Promotion of government industry } \\
\text { research }\end{array}$ & 6.8 & 7.9 & 8.9 & $(+12.6)$ \\
\hline Research fellowships & 0.8 & 1.1 & 1.5 & $(+30.1)$ \\
\hline Nuclear fusion & 8.2 & 7.7 & 7.6 & $(-1.2)$ \\
\hline Accelerator physics (TRISTAN) & 13.0 & 12.9 & 16.5 & $(+28.2)$ \\
\hline Space science & 12.4 & 11.8 & 19.8 & $(+67.4)$ \\
\hline Marine science & 0.5 & 3.0 & 5.5 & $(+84.0)$ \\
\hline Earth science & 2.0 & 2.1 & 2.1 & $(+1.0)$ \\
\hline Antarctic research & 3.1 & 2.9 & 2.8 & $(-1.7)$ \\
\hline Cancer research & 1.8 & 1.8 & 2.2 & $(+19.9)$ \\
\hline Information networks & NA & 17.2 & 19.0 & $(+10.1)$ \\
\hline International academic exchange & NA & 5.5 & 6.6 & $(+19.8)$ \\
\hline International student exchange & 11.7 & 14.5 & 18.3 & $(+26.0)$ \\
\hline Japanese language education & 0.2 & 0.3 & 0.3 & $(+1.5)$ \\
\hline
\end{tabular}

years, the ministry is still slowly proceeding with plans to establish a new national institute for basic research on fusion in Gifu prefecture that will have a helical conductor system as its main facility; $¥ 50$ million is set aside in fiscal 1988 in "preparation funds".

The budget for international exchange leaps by nearly $¥ 5,000$ million ( $\$ 40$ million). Japan has recently come under criticism for sending too many scientists each year to the United States, France, West Germany and the United Kingdom, with too little traffic the other way. The number of domestic postdoctoral fellowships is similarly increased by 80 , with 404 new 2-year fellowships in fiscal 1988. But the postdocs may be envious of their Western colleagues - while they have to survive on $¥ 717,000$ a month (equivalent to about $\$ 20,000$ a year) the overseas visitors get close to $\$ 30,000$ a year, tax free.

The budget for marine research has swollen by an order of magnitude compared with that of 1986 , but all the extra money is going towards construction of a

Industry which were held to meagre increases despite an expansionary budget for fiscal 1988 (see Nature 331, 198; 1988).

Grants-in-aid for scientific research are boosted by nearly $¥ 4$ thousand million (\$30 million). Half of the increase goes to grants in the category "priority areas of research", which supports projects involving large numbers of scientists from all over Japan. For example, several hundred million yen will go to a 3-year investigation of the new high-temperature superconductors by a team led by Professor Muto of Tohoku University, who has links with Shoji Tanaka's group at Tokyo University. Tanaka also received a large grant for research on the new superconductors from the ministry this fiscal year.

TRISTAN, the world's largest electron-positron collider, which began fullscale experiments in May, gets several thousand million yen extra in fiscal 1988 to increase operating hours and to boost power through the emplacement of superconducting radio-frequency cavities. And, although funds for fusion research have steadily declined over the past 3 new research vessel for Tokyo University.

Several thousand million extra yen are also being ploughed into the development of information networks in the national universities and into promotion of joint university/industry research. But by far the largest budgetary increase is for space research. The ministry's Institute of Space and Astronautical Sciences gets a massive boost of $¥ 8,000$ million (about $\$ 60$ million) over last year. In part the increase can explained by the fact that the institute did not launch any satellites in the present fiscal year. Nevertheless, the budget is by far the highest ever.

The institute has had a string of major successes over the past few years - the Halley's comet probes in 1986 and the Xray satellite Ginga which detected X-rays from the supernova in the Magellanic Cloud at the end of last year (see Nature 330, 230; 1987). And the institute is now angling for a bigger rocket to send probes to the planets. But the extra funds in 1988 are nearly all for satellite programmes which have already been approved and use existing rocketary. David Swinbanks
SSC shortlist now cut down to seven sites

\section{Washington}

THE US Department of Energy (DoE) has officially accepted the shortlist of sites for the Superconducting Supercollider (SSC) that was recommended by the National Academy of Sciences (see Nature 331, 2: 1988). But the final list has only seven sites - one each in Texas, Illinois, Arizona, Colorado, Michigan, Tennessee and North Carolina - because New York Governor Mario Cuomo asked DoE to remove from further consideration the state's proposal to build the SSC near Rochester.

Cuomo was responding to the wishes of local residents and congressmen, who are in opposition to disruption of the rural area, and takes New York, which originally had four prospective sites, out of the running.

New York's bid for SSC, led chiefly by Lieutenant Governor Stan Lundine, has been ill-starred. One site was rejected because it crossed into Canada, and another was withdrawn earlier after a noisy town meeting. Cuomo asked DoE to reconsider the fourth New York site, which did not make the shortlist, but DoE was evidently unwilling to tinker with the academy's selection and risk protests from the many other states that were left out. In any case, Cuomo has never made any strong public expression of support for SSC, and did not press DoE hard on New York's behalf.

Unlike New York, California officials had been keen to host the SSC, and had pushed hard but unsuccessfully to be added to the DoE shortlist after the academy committee passed it over. Thomas Everhart, president of the California Institute of Technology and a member of the academy selection committee, said the committee felt that the proposed California site, near Stockton, had a number of problems, not least of which was its distance from a major international airport.

The committee felt SSC should be located where it can be easily reached by scientists from around the world. After a site was determined to be acceptable in geological terms, ease of access and regional resources weighed heavily in the committee's deliberations.

Everhart said the Illinois site near Chicago, and the Texas site near Dallas, both provide excellent travel facilities. The committee was concerned about the question of local opposition, but did not include this in the decision process.

David Lindley \& Joseph Palca 